\title{
PENGEMBANGAN APLIKASI PROGRESSIVE WEB APPLICATION (PWA) UNTUK PEMBELAJARAN DAN EVALUASI KELAS ENGLISH GRAMMAR ONLINE COURSE
}

\author{
Gharizi Matiini'), Rahmat Setiyadi' $^{2)}$, Adi Setiawan ${ }^{3)}$, M. Ramli') \\ )Prodi Teknik Mesin Otomotif, Institut Teknologi Indonesia, Indonesia \\ gharizi.matiini@iti.ac.id \\ 2) Prodi Teknik Sipil, Institut Teknologi Indonesia, Indonesia \\ rahmat.setyadi@iti.ac.id \\ 3) Prodi Teknik Elektro, Institut Teknologi Indonesia, Indonesia \\ Adi.setiawan@iti.ac.id \\ 4) Prodi Informatika, Institut Teknlogi Indonesia, Indonesia \\ ramli@iti.ac.id
}

\begin{abstract}
Abstrak: Penelitian ini bertujuan untuk mengembangkan sistem E-Learning Bahasa Inggris menggunakan Aplikasi PWA (Progressive Web Application). Aplikasi ini sendiri tidak perlu diunduh terlebih dahulu melalui Play Store melainkan menggunakan situs Pusat Bahasa ITI. Uji coba diadakan dalam bentuk pembelajaran E-Learning yang dikhususkan kepada English Grammar menggunakan Digital Book sebagai buku pegangan. Partisipan dari kelas English Grammar ini adalah mahasiswa Institut Teknologi Indonesia tingkat dua. Aplikasi PWA menjadi media pembelajaran E-Learning, dimana seluruh partisipan dapat menggunakan ponsel pintarnya untuk belajar, test, dan mengisi kuesioner pembelajaran. Hasil dari penelitian ini adalah bahwa aplikasi PWA ini terbukti efektif menjadi salah satu media pembelajaran jarak jauh dan lebih mudah diakses daripada aplikasi lain yang diunduh melalui Play Store. Namun untuk evaluasi pembelajaran dari kelas English Grammar masih harus dikembangkan lebih jauh agar dapat disesuaikan dengan kebutuhan dosen dan mahasiswa.
\end{abstract}

Kata Kunci: PWA, ecOURSE, English Grammar, Evaluasi

\begin{abstract}
The study aims to develop E-learning system of English subject using PWA application (Progressive Web Application). This application does not need to be firstly downloaded via Play Store. Instead it can be stamped from ITI's English Language Center site. The experiment was conducted in the form of E-learning class focusing on the English Grammar using digital book as the learning textbook. The participants of the E-Learning were sophomore students of Institut Teknologi Indonesia. The PWA app became the Learning media of the class where all participants could used their smart phones to study, to take the test, and to fill out the questionnaire of the learning. The result of the study is that the PWA app was proved to be effective as one of the online learning media and it could be more easily accessed than other play store apps. However, for learning evaluation from the English Grammar class, it needed to be more developed and prepared so that it would be suitable for every lectures' and students' needs.
\end{abstract}

Keywords: Kata Kunci: PWA, ecOURSE, English Grammar, Evaluation

\section{PENDAHULUAN}

Pesatnya perkembangan ilmu dan teknologi pada abad ke-21 ini melahirkan era yang disebut Revolusi Industri 4.0 Salah satu perkembangan yang tampak kasat mata adalah lahirnya teknologi komunikasi dan informasi $4 \mathrm{G}$ yang sebentar lagi juga akan tergantikan dengan kemunculan 5G di tahun 2020.

Ahonen (2011) dalam penelitiannya menyatakan bahwa pengguna telepon cerdas rata-rata melihat telepon cerdasnya 
sekitar 150 kali per hari. Di antara aktivitas yang dilakukannya adalah: terkait pengiriman pesan 23 kali per hari, terkait panggilan suara 22 kali, jam 18 kali, pemutar musik 13 kali, game 12 kali, media sosial 9 kali, alarm 8 kali, kamera 8 kali, berita dan pemberitahuan 6 kali, kalender 5 kali, pencarian 3 kali per hari, penjelajahan acak web lain 3 kali, men-charge telepon 3 kali, voice mail 1 kali, pemakaian lainnya 10 kali (atau mencapai 6,7\%).

Terlihat bahwa peluang mengoptimalkan fungsi gadget dalam hal "pemakaian lainnya" cukup besar, mencapai $6,7 \%$. Prosentase ini masih lebih tinggi daripada penggunaan gadget untuk beraktivitas di medsos, memakai kamera atau membaca berita. "Pemakaian lainnya" ini tentunya bisa dimaknai salah satunya sebagai penggunaan dalam bidang pendidikan, lebih khusus lagi untuk keperluan eLearning.

Pada dasarnya ada begitu banyak platform pembelajaran Bahasa Inggris berbasis Android maupun IOS. Terlebih Bahasa Inggris dapat dipelajari tak hanya melalui pengajar lokal, namun juga pengajar native. Pembelajaran Online tentu saja mempermudah pembelajar Bahasa Inggris untuk mengasah kemampuan Bahasanya. Hanya saja pembelajaran online memiliki satu kekurangan yang sangat umum dan menjadi batu sandungan pembelajar Online, yaitu biaya internet dan pulsa data. Terlebih beberapa aplikasi belajar Bahasa Inggris di Android dan IOS mengharuskan pembelajar untuk membayar biaya unduhan dan biaya langganan. Nurwanto (2019) menemukan bahwa terdapat kesenjangan antara Aplikasi Native dan Web Standar. Oleh karena itu biasanya pelajar lebih sering memakai aplikasi berbasis web yang pemakaian data internetnya jauh lebih mudah dan praktis ketimbang memakai aplikasi Android dan IOS. Lebih jauh, Karpagan (2017) menyatakan bahwa keterbatasan Browser Seluler dan Aplikasi Native membuat banyak pihak mengembangkan alternatif teknologi pembelajaran yang jauh lebih murah dan efektif.

Atas permasalahan itulah, kami tertarik melakukan suatu penelitian dalam bidang pembelajaran Bahasa Inggris berbasis online yang lebih murah dan praktis. Dalam penelitian ini, kami akan memanfaatkan Progressive Web Application (PWA). Santoso (2019) menyatakan bahwa Progressive Web Application adalah suatu teknologi berbasis Website yang dirancang berdasarkan teknologi Web Modern, akan tetapi dapat dijadikan sebuah mobile app. Berbeda dengan native app berbasis Android yang hanya dapat berjalan di sistem operasi Android, PWA ini dapat di-install pada sistem operasi Android maupun iOS. Kurniawan, dkk. (2017) pernah menyatakan bahwa pada dasarnya PWA merupakan aplikasi berbasis Web biasa, namun memanfaatkan fitur peramban modern yang modern seolah-olah merupakan Aplikasi Native. Dalam penelitian Majcrzak, et al. (2018) yang yang mengemukakan bahwa seiring terjadinya kesenjangan antara Aplikasi Native dan Web Standar, maka nantinya PWA bisa menjadi pemersatu dalam pengembangan Aplikasi Native dan Web Standar.

Terdapat beberapa penelitian Aplikasi PWA yang telah dilakukan, diantaranya Chan \& Sumaryana (2019) dalam penelitian mereka tentang penggunaan PWA sebagai aplikasi Lowongan Dosen mendapatkan hasil bahwa PWA dapat diakses dalam koneksi yang tidak stabil dan offline sehingga memudahkan para pencara pekerjaan untuk mengakses ke situs lowongan kerja mereka. Namun diantara hasil positif dari penelitian PWA, terdapata pula penelitian yang menyatakan kekurangan dalam penggunaan aplikasi PWA. Kurniawan (2020) dalam identifikasi performa PWA di perangkat Mobile menemukan bahwa ternyata PWA 
belum pasti menjadi solusi dalam masalah cross-platform yakni perpindahan dari suatu browser ke browser lainnya dengan mudah dan cepat, Hal ini dikarenakan belum seimbangnya penelitian dan survey antara ekxperimental dan kualitatif dari pengembangan aplikasi PWA.

Tujuan dari penelitian ini adalah menghasilkan suatu aplikasi yang dapat berjalan pada sistem operasi Android dan iOS berupa PWA dengan memanfaatkan website Pusat Bahasa ITI sebagai media pembelajaran Bahasa Inggris dan melakukan evaluasi terhadap English Grammar Online Course yang telah diujicobakan. Sebagai tambahan dalam indentifikasi keefektifan aplikasi PWA dalam English Grammar Online Course ini, peneliti juga melakukan evaluasi penilaian English Grammar pada partisipan yang mengikuti kelas ini. Evaluasi ini juga dilaksanakan dalam rangka mencari review dan pendapat para partisipan setelah menggunakan aplikasi PWA selama pembelajaran. Jika menurut mereka Aplikasi PWA efektif dijadikan platform pembelajaran, maka untuk seterusnya aplikasi ini dapat dijadikan alternatif pembelajaran online.

Hingga saat ini terdapat sekitar 4 juta aplikasi yang terdapat di Google Playstore dan Apple Store. Jika sebuah aplikasi harus di-download ke perangkat pengguna melalui kedua toko online tersebut, aplikasi tersebut dikenal dengan nama native app. Jenis aplikasi ini biasanya menawarkan pengalaman pengguna yang baik, yakni waktu loading yang cepat dan jika tidak ada jaringan, kebanyakan aplikasi tersebut masih bisa digunakan karena sebagaian besar sumber daya yang dibutuhkan telah tersimpan dalam perangkat tersebut.

Kebalikan dengan native app tersebut, secara historis sebuah website (situs) tidak dapat menawarkan pengalaman pengguna sebaik yang ditawarkan oleh native app, yakni kemampuan pada saat offline, waktu loading yang cepat dan keandalan yang cukup tinggi. Hal inilah yang menyebabkan sejumlah pengembang browser bekerjasama untuk menciptakan seperangkat fitur yang bisa membantu para pengembang website membuat web secara cepat, dapat diandalkan dan aman. Di sinilah kemudian lahir yang namanya PWA (Progressive Web App)

Salah satu alasan mengapa peneliti memilih memanfaatkan Aplikasi PWA ini adalah karena kemudahan untuk mengakses yang disajikan oleh PWA tanpa harus mendowload melalui play store, kita sudah dapat menjadikan Website Pusat Bahasa sebagai Display Icon sehingga kita hanya perlu klik Icon Pusat Bahasa ITI kemudian Website tersebut sudah dapat digunakan layaknya sebuah aplikasi Native. Tandel \& Jamadar (2018) dalam penelitian mereka, telah menemukan bahwa mengakses melalui PWA dapat menghemat memori Seluler namun dengan kecpatan akses yang lebih cepat dibandingkan denga Web Standar.

Pembelajaran menggunakan sistem E-Learning saat ini sedang menjadi ikon baru dalam dunia pendidikan di Indonesia. Kementrian Pendidikan dan Kebudayaan pun sudah mulai mengglakkan sistem penbelajaran ini di setiap perguruan tinggi. Sejak tahun 2008, UNESCO menyatakan bahwa lebih dari 455 juta penduduk di seluruh dunia menerima pendidikan dan pelatihan melalui internet. Pembelajaran $E$ learning sendiri merupakan suatu sistem pendidikan yang memanfaatkan teknologi informasi dalam proses belajar mengajar tanpa melalui proses tatap muka secara langsung antara dosen dan mahasiswa (Michael,2013; Chandrawati,2010; Ardiansyah, 2013).

Namun, dikarenakan sistem ini masih tergolong baru, masih banyak perguruan tinggi yang menkombinasikan sistem ini menggunakan sistem Blended Learning dimana masih ada tatap muka dalam prose's belajar mengajar. Hal ini 
terjadi karena masih adanya keraguan dari perguruan tinggi mengenai keberhasilan menggunakan sistem ini. Padahal menurut penelitian Sianturi (2018) yang telah melakukan observasi dan wawancara dengan mahasiswa di jurusan keperawatan yang sudah melakukan E-learning menyatakan bahwa mereka lebih menginginkan metode pembelajaran yang inovatif dan interaktif dan sesuai dengan perkembangan teknologi yang saat ini mereka hadapi. Hal ini berkesesuaian dengan tujuan E-Learning yang dimana menggunakan teknologi untuk mempermudah proses belajar-mengajar.

Oleh karenanya stigma tersebut dapat diatasi dengan beberapa regulasi dan kriteria agar tujuan pembelajaran dapat tercapai. itu Onno Purbo (2002) mensyaratkan tiga hal yang wajib dipenuhi dalam merancang elearning, yaitu sederhana, personal, dan cepat. Sederhana disini berarti perangkat teknologi yang digunakan oelh peserta didik harus yang mudah diakses dan efisien dalam pemakaiannya, yang berarti tidak memberatkan peserta didik itu sendiri. Personal mengartikan dengan menggunakan pendekatan E-learning akan lebih memudahkan interaksi antara dosen dan mahasiswa, yang berarti semakin besar kemungkinan pesan pembelajaran yang ingin disampaikan pendidik serta pendidikan dapat lebih mudah mengawasi kemajuan dalam pembelajaran peserta didik. Sementara cepat adalah respon yang dapat dengan udah dilakukan antara dosen dan mahasiswa serta operator yang memudahkan teratasinya setiap masalah selama proses belajar mengajar.

Selain itu Strategi atau metode pembelajaran yang diciptakan oleh dosen harus menjawab kebutuhan tesebut dan tren terbaru dalam pendidikan tinggi dengan membangun pembelajaran yang berkesuaian dengan sistem elearning (Irawati \& Putra, 2014). Oleh sebab itu baik dosen maupun mahasiswa haruslah menguasai terlebih dahulu segala perangkat pembelajaran berbasis E-Learning yang akan digunakan

Penggunaan Sistem E-Learning tentu tak lepas dari hasil yang positif maupun negatif. Beberepa perguruan tinggi telah banyak menggunakan sistem ini dan telah mendapatkan banyak manfaat dari penggunaan sistem ini. Salah satu perguruan tinggi yang sudah memanfaatkan sistem ini adalah Universitas Terbuka. Universitas Terbuka (UT) sebagai perguruan tinggi jarak jauh sudah memanfaatkan e-learning sebagai media pembelajaran, seperti tutorial online, suplemen berbasis web, latihan mandiri, kit tutorial, dan sebagainya. Makalah ini merupakan telaah pemanfaatan teknologi dan informasi berbasis e-learning pada pendidikan tinggi jarak jauh (Islamiyah \&Widayanti, 2016). Dalam Penelitian mereka, menghasilkan efektifitas penggunaan Sistem E-Learning dan hasil akhir dari sistem pmbelajaran jarak jauh ini adalah telah dibuatkan Web-Based Program untuk E-Learning yang mudah diakses oleh seluruh Civitas Akademika Universitas Terbuka dan diakui se Asia Tenggara.

Hasil lain dari penggunaan sistem ELearning adalah terbentuknya variasi dalam metode pembelajaran dengan menggunakan elearning bagi kalangan mahasiswa pada saat ini yang ternyata dirasakan mampu menjawab kebutuhan mahasiswa sehingga proses pembelajaran menjadi lebih menarik (Sianturi \& Lisum, 2018). Hal lain yang didapat dari Pembelajaran ini adalah meningkatnya minat dan motivasi mahasiswa dalam belajar yang membuat proses belajar-mengajar menjadi tidak membosankan.

Hasil negatif yang mungkin saja didapat dari pembelajaran menggunakan sistem E-Learning adalah kemungkinan hilangnya value pendidik yang biasa didapat dari interaksi langsung antara dosen dan mahasiswa (Bullen, 2001), Tuntutan besar bagi dosen untuk 
menguasai Teknik Komputer serta perkembangan teknologi lainnya juga bisa jadi batu sandungan untuk penggunaan sistem ini. Hal negatif lainnya dari sistem ini dan masih terjadi di Indonesia adalah kurang nya kelengkapan sumber daya untuk menjalankan sistem ini. Tentu tak semua perguruan tinggi memiliki fasilitas E-Learning yang lengkap dikarekan kurangnya Anggaran biaya, SDM, atau bahkan lahan dan ruangan

\section{METODE PENELITIAN}

\section{Rancangan Penelitian}

Karena penelitian ini bersifat Paralel; penelitian kelas dan penelitian eksperimen, membutuhkan waktu cukup lama dalam menyelesaikannya. Identifikasi penggunaan Aplikasi PWA serta memastikan kesiapan Website Pusat Bahasa sebagai Icon Display adalah hal pertama yang dilakukan dalam penelitian ini. Setelah PWA Pusat Bahasa dirasa siap kemudian dilaksanakan pelaksanaan penelitian kelas Berbasis Daring menggunakan PWA Pusat Bahasa. Setelah satu semester pembelajaran, Evaluasi dilakukan melalui beberapa tahap: (1) Identifikasi memori dan kecepatan akses penggunaan PWA Pusat Bahasa; (2) Idetifikasi hasil pembelajaran partisipan; (3) Identifikasi keefektifan penggunaan PWA Pusat Bahasa dari perspektif partisipan. Setelah itu akan dihasilkan beberapa prosentase, diagram, dan hasil qualitatif dari partisipan mengenai Aplikasi PWA Pusat Bahasa.

\section{Sumber Data}

Dalam Penelitian ini, Terdapat dua jenis data yang akan diambil, yaitu data service work yang diambil dari hasi akses PWA serta hasil evaluasi Pembelajaran Bahasa Inggris menggunakan PWA. Service Work akan berupa jumlah memori dan kecepatan yang dihasilkan dari aplikasi PWA dalam mengakses Website Pusat Bahasa ITI. Sedangkan Hasil evaluasi berupa nilai Hasil Pembelajaran, Questionnaire Pembelajaran, serta testimoni dari peserta pembelajaran. Aplikasi PWA yang dipakai diambil dari Android ataupun IOS systemn diatas 7.0. dan website yang dipakai adalah pb.iti.ac.id.

Partisipan merupakan mahasiswa Insitut Teknologi Indonesia semester 5 pada saat itu. Setiap dari mereka telah memiliki telepon selular yang ber Android diatas 7.0. Jumlah partisipan dalam penelitian ini adalah 10 orang.

\section{Teknik Pengumpulan Data}

Penelitian ini diawalai dengan studi literatur dilakukan untuk mengawali dan menggali lebih jauh mengenai PWA, sistem operasi Android dan iOS, teknologi mobile, serta pengembangan sistemnya. Setelah mengidentifikasi kelebihan dan kekurangan dari aplikasi PWA, peneliti kemudian mengcari partisipan dari Mahasiswa kampus ITI yang saat itu akan mengulang kelas Bahasa Inggris namun, waktu mereka tersita dari mata kulliah lain. Sebelum menempuh kelas ini, partisipan di pertemukan guna memastikan bahwa mereka siap mengikuti kealas percobaan ini selama satu semester penuh. Mereku juga diyakinkan untuk selalu menggunakan telepon selular nya dalan setiap pembelajaran agar data Service Work dapat diambil dari hasil akses mereka.

Selama percobaan pembelajaran English Grammar eCourrse menggunakan sistem jarak jauh, terdapat Digital Book yang dijadikan bahan ajar dalam kelas ini dan terdapat tiga test berbeda yang diberikan pada waktu yang berbeda yang diberikan juga melalui portal ini. Terdapatadua level berbeda yang dibagai dalam dua kelas sehingga dosen, Digital Book, serta test pun diberikan berbeda dari satu level ke level lain. Partisipan dalam hal ini merupakn mahasiswa Institut Teknologi Indonesia yang pada saat pembelajaran berlangsung, sedang menempu tingkat kedua mereka. Peserta didik diberikan 25 jam pembelajaran selama satu semester ini dan pada akhirnya mereka harus menyelesaikan tiga test yang ketiganya 
harus mereka jawab dengan benar agar dapat lulus dalam kelas ini.

Untuk mengevaluasi pembelajarn jarak jauh ini, peneliti membuat dua instrumen lain selain tiga jenis test yang berbeda. Keduanya berupa kuesioner dan testimony yang keduanya diolah dan dianalisis untuk menemukan titik temu dalam pengembangan sistem E-Learning berbasi PWA. Kuesioner diberikan setelah seluruh peserta didik menyelesaikan seluruh 25 jam pembelajaran dan ketiga test yang diberikan dosen masing-masing level. Tak lupa hasil evaluasi ini akan dilaporkan pada lembaga LP2V dan PB ITI sebagai pihak yang bekerja sama dengan peneliti.

\section{Analisis Data}

Setelah seluruh data didapat, peneliti pertama-tama akan menghitung memori dan kecepatan akses data selama pembelajaran berbasis PWA berlangsung. Hasil hitungan ini dapat diambil dari penguaturan di setiap telepon selular partisipan, serta dari History Website Pusat Bahasa. Hasilnya akan prosentase dan dibandingkan dengan teori PWA dipenjelasan sebelumnya. Untuk Hasil Evaluasi Pembelajaran, analisisnya akan berupa seberapa efektif pembelajaran English Grammar menggunakan PWA serta seberapa puas para partisipan mengikuti Pembelajaran online tersebut. Y

\section{HASIL PENELITIAN}

Dalam bab ini, akan dipaparkan dua hasil penelitian Pengembangan Aplikasi PWA. Dua hasil penelitian tersebut dikarenakan dua pendekatan penelitian yang berbeda untuk mendapatkan hasil yang lebih maksimal sehingga signifikansinya dapat lebih terlihat. Dua hasil tersebut adalah; (1) Hasil identifikasi dari Service Work Aplikasi PWA yang didapat dari Jumlah memori dan kecepatan akses dari telepon seluler dan Website Pusan Bahasa saat dibuka menggunakan Aplikasi PWA; serta (2) Hasil Evaluasi Pembelajaran dan Kepuasan partisipan selama belajar English Grammar menggunakan Aplikasi PWA.

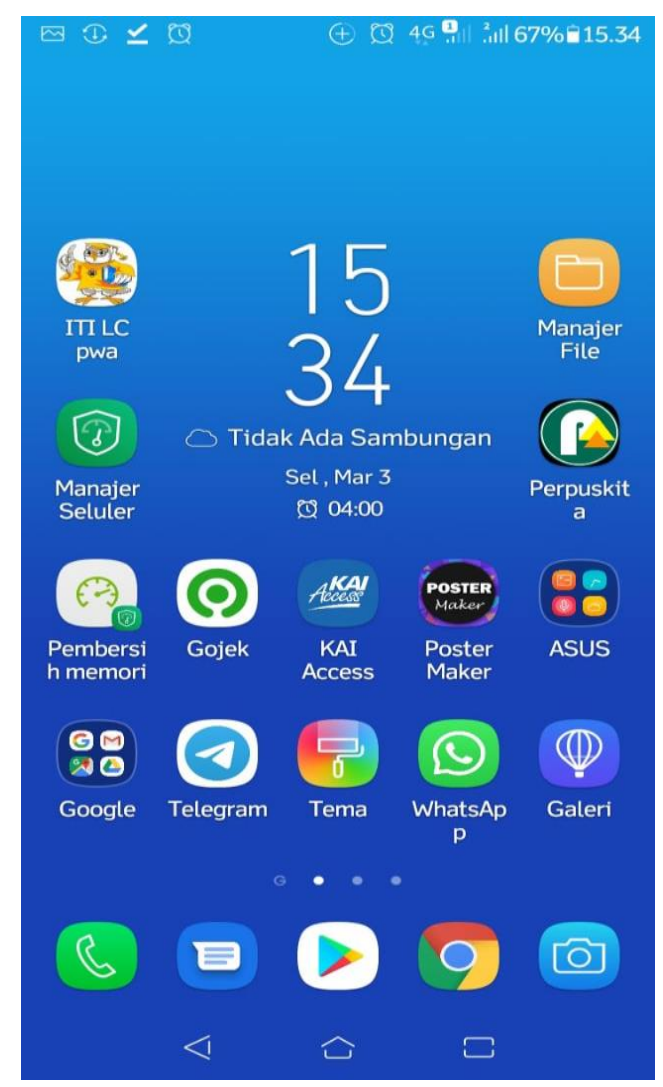

Gambar 1. Screenshot PWA di Android 8 


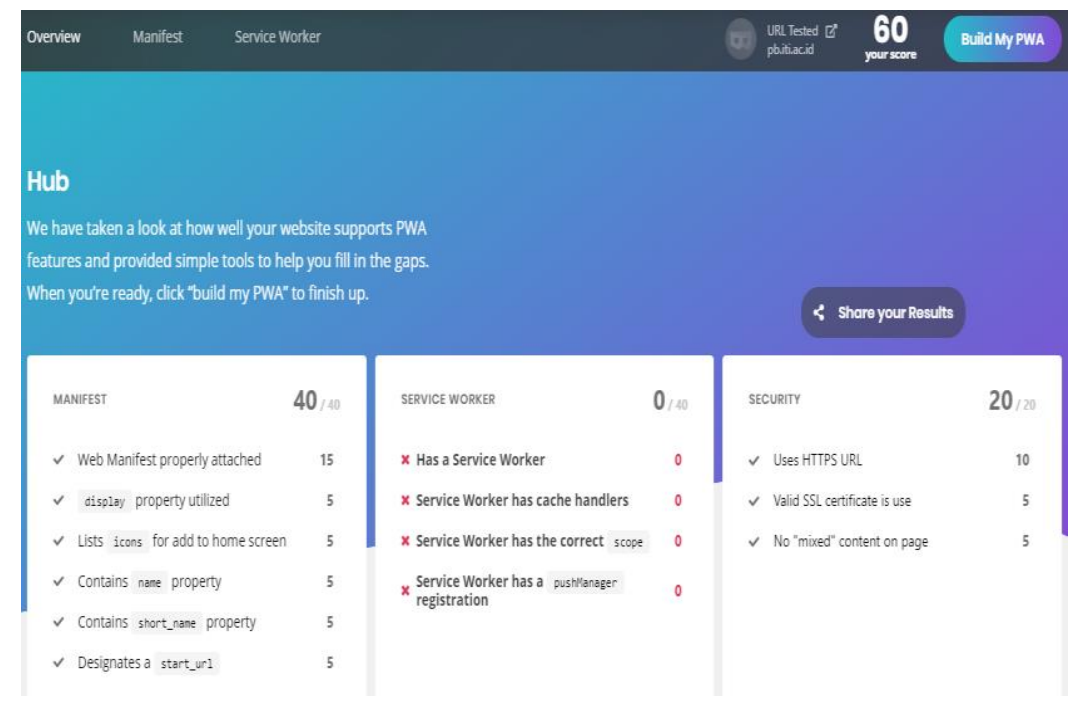

Gambar 2.Pengujian dengan PWABuilder

Pengujian website Pusat Bahasa ITI dengan PWABuilder mendapatkan skor total 60/100, di mana untuk service worker tidak terdeteksi (nilai 0/20). Kekurangan service worker ini menyebabkan jika website Pusat Bahasa ITI (https://pb.iti.ac.id) dalam kondisi offline, maka di sisi aplikasi pengguna akan offline juga. Sebagai informasi, Indentifikasi PWA Builder ini sudah melalui tahap ujicoba sebelumnya pada penelitian pertama kami yang mengikutsertakan peneliti dan dosen dan Program Studi Informatika. Penelitian sudah atas ujicoba dan saran dari para peneliti dan dosen Informatika tersebut meskipun untuk peneliti dari Media dan Broadcasting tidak kami ambil ujicobanya, dikarenakan keterbatasan waktu dan biaya dalam pengkajian lebih jauh mengenai indentifikasi PWA ini.

Ke depannya akan ditambahkan mekanisme service worker untuk mendapatkan layanan jika website dalam kondisi offline atau tidak bisa diakses, maka disisi pengguna mobile masih bisa diakses. Dua aspek lainnya, yaitu manifestasi dan keamanan lulus dalam pengujian dengan nilai maksimal $40 / 40$ untuk manifes dan 20/20 untuk keamanan.

\section{Content breakdown by MIME type (First View)}
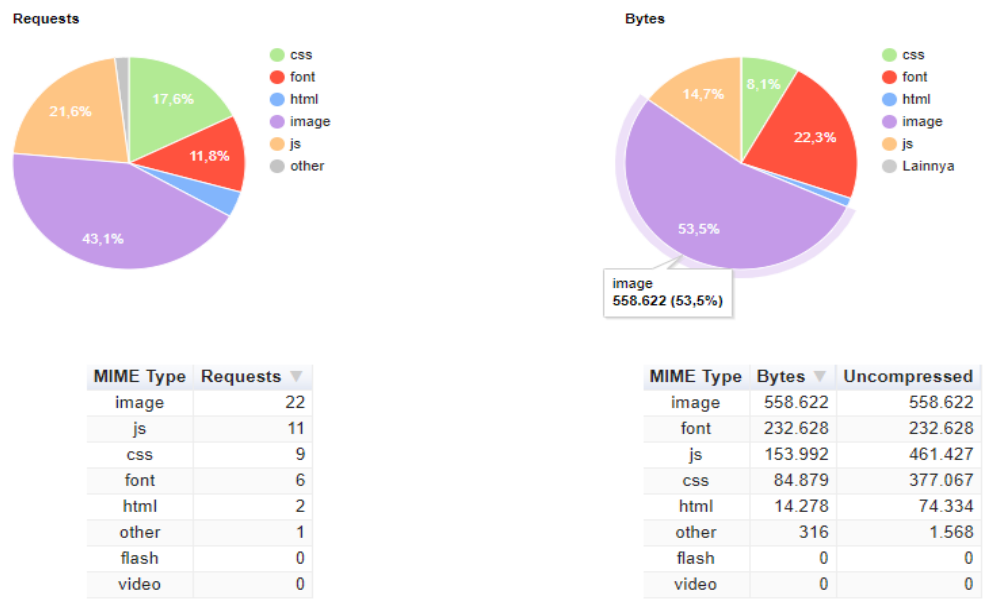

Gambar 3. Hasil Analisis Konten Website Pusat Bahasa ITI 
Dari analisis terhadap konten website seperti ditunjukkan pada Gambar 3, sebagian besar konten dipenuhi dengan gambar (53.5\%) yang membuat first byte time menjadi lambat. Namun gambar-gambar setelah dicache dan dikompres dari sisi server maka akses akan jauh lebih cepat untuk request ke dua dan seterusnya.

Setelah menjalankan program $E$ Learning menggunakan media Digital book, dihasilkan beberapa analisis. Sebagai informasi, jumlah peserta E-Learning ini berjumlah 9 orang dengan pembagian kelas (1) Basic Level sebanyak Lima orang dan (2) Intermediate level sejumlah empat orang. Berikut adalah hasil analisa penilaian, Quesioner, Saran, dan Testimoni dari seluruh peserta E-Learning English Grammar ini

Tabel 1. Hasil Penilaian Kelas Level I

\begin{tabular}{|l|ll|l|l|l|}
\hline & Test 1 & Test 2 & Test 3 & Nilai Akhir & Grade \\
\hline $\mathrm{F}$ & 40 & 70 & 30 & 40 & $\mathrm{E}$ \\
\hline $\mathrm{R}$ & 90 & 100 & 40 & 62 & $\mathrm{C}+$ \\
\hline $\mathrm{M}$ & 90 & 90 & 70 & 78 & $\mathrm{~A}-$ \\
\hline $\mathrm{N}$ & 90 & 100 & 60 & 74 & $\mathrm{~B}+$ \\
\hline $\mathrm{V}$ & 70 & 50 & 60 & 60 & $\mathrm{C}$ \\
\hline
\end{tabular}

Tabel diatas adalah hasil akhir dari pembelajaran English Grammar menggunakan E-course. Terdapat tiga test yang diadakan dalam E-Learning ini yang dilakukan dalam waktu yang berbeda. Tiap test mengandung beberapa bab dari pembahasan dalam Digital Book. Tabel ini menunjukkan bahwa seluruh peserta telah secara resmi lulus dari kelas ini dengan nilai paling kecil adalah 60 atau $C$ dan nilai tertinggi adalah A- dengan nilai 78

Grafik 1 Hasil Penilaian Kelas Level 1

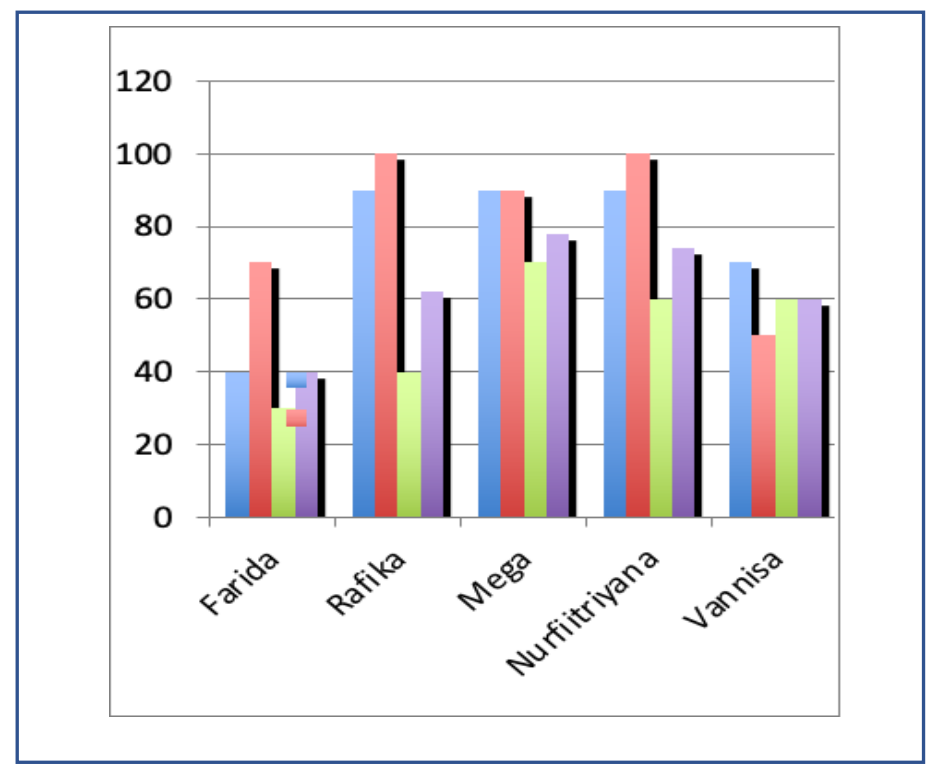

Hasil grafik dapat dilihat bahwa terjadi fluktuasi nilai dari seluruh mahasiswa level satu mulai dari test pertama hingga ketiga.
Hasil fluktuatif menunjukkan bahwa ada beberapa bab pembahasan yang mungkin saja masih belum bisa dimengerti oleh 
peserta didik hingga mereka tidak mampu mendapatkan nilai terbaik dari hasil belajar mandiri mereka. Nilai paling tinggi dari peserta didik terdapat dalam test 2 yang mengartikan bahwa bab 2 dan 3 adalah materi yang paling mudah dimengerti oleh peserta didik. Sementara untuk test lainnya, peserta didik terlihat kesulitan dalam mengerjakannya.

Tabel 2. Hasil Penilaian Kelas Level II

\begin{tabular}{|c|c|c|c|c|c|}
\hline & Test 1 & Test 2 & Test 3 & Nilai Akhir & Grade \\
\hline F & 80 & 80 & 85 & 82,75 & A \\
\hline S & 80 & 90 & 85 & 85,25 & A \\
\hline I & 70 & 70 & 80 & 75,5 & B+ \\
\hline A & 90 & 90 & 80 & 84,5 & A \\
\hline
\end{tabular}

Dari tabel tersebut, dapat dilihat bahwa hampir seluruh mahasiswa dalam kelas lavel II mengalami peningkatai nilai dari waktu ke waktu. Pada Test pertama hampir seluruh mahasiwa level tersebut mendapatkan nilai minimal 80. Kemudian Nilai mereka meningkat seiring dengan bertambahnya jumlah hingga ke test terakhir mereka. Pada nilai di test ketiga hampir seluruh nilai mahasiswa ini mengalami penurunan meskipun tidak signifikan, sehingga kesimpulan yang dapat diambil pada hasil nilai kelas level dua adalah adanya peningkatan nilai dari test ke test.

\section{Grafik 2. Hasil Penilaian Kelas Level 2}

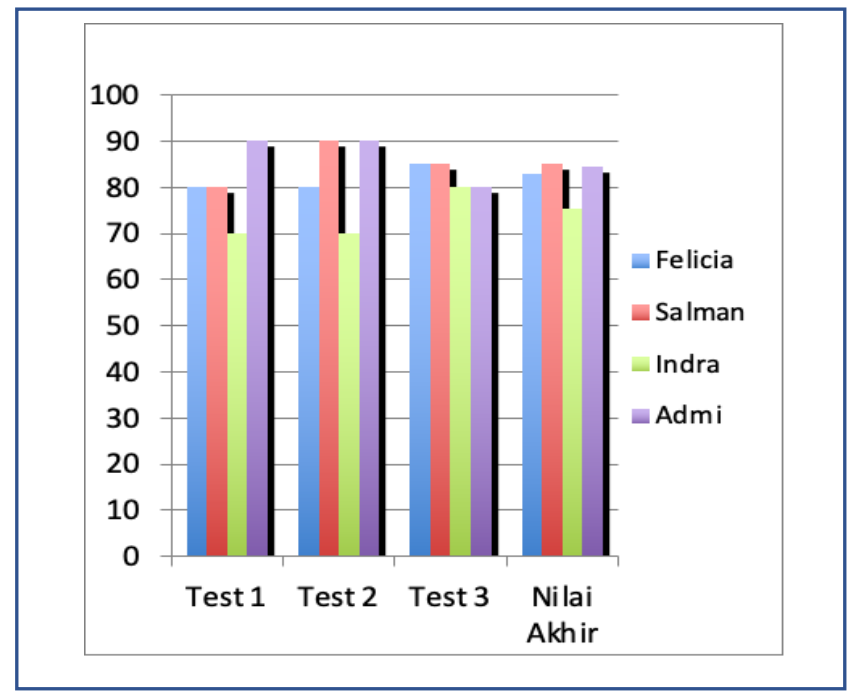

Berdasarkan grafik, dapat dilihat bahwa secara kesuluruhan mahasiwa level

nilainya hingga ke test ketiga. Hal ini mengindikasikan bahwa rata-rata mahasiswa kelas level dua dapat mencerna buku digital grammar Bahasa Inggris dan dapat dikatakan mereka merasa nyaman dengan konten dan informasi dari Buku Digital tersebut.

Hasil Evaluasi Berdasarkan Kuesioner dan Testimoni

Setelah pembelajaran usai dan semua test telah dilaksanakan, peserta didik diharuskan 
untuk mengisi form kuesioner dalam rangka peningkatan mutu sistem E-Learning di ITI.
Berikut adalah hasil akhir dari kuesioner yang telah disampaikan

Tabel. 3. Hasil Quesioner Peserta E-Learning English Gramma

\begin{tabular}{|c|c|c|c|}
\hline \multicolumn{4}{|c|}{ MATERI PEMBELAJARAN } \\
\hline NO & PERTANYAAN & SETUJU & $\begin{array}{l}\text { TIDAK } \\
\text { SETUJU }\end{array}$ \\
\hline 1. & $\begin{array}{l}\text { E-book yang digunakan menyediakan penjelasan } \\
\text { dan contoh yang cukup lengkap }\end{array}$ & $100 \%$ & - \\
\hline 2. & E-book menyediakan materi yang up-to date & $100 \%$ & - \\
\hline 3. & $\begin{array}{l}\text { E-book menggunakan bahasa } \\
\text { dipahami }\end{array}$ & $100 \%$ & - \\
\hline 4. & E-book menyediakan isi yang bermanfaat & $100 \%$ & - \\
\hline \multicolumn{4}{|c|}{ MEDIA PEMBELAJARAN } \\
\hline NO & PERTANYAAN & SETUJU & $\begin{array}{l}\text { TIDAK } \\
\text { SETUJU }\end{array}$ \\
\hline 1. & $\begin{array}{l}\text { Penggunaan Aplikasi Whatsapp cukup efektif } \\
\text { selama pembelajaran }\end{array}$ & $71 \%$ & $29 \%$ \\
\hline 2. & $\begin{array}{l}\text { Aplikasi yang digunakan bisa menyampaikan } \\
\text { bimbingan/informasi yang jelas selama } \\
\text { pembelajaran }\end{array}$ & $86 \%$ & $14 \%$ \\
\hline 3. & $\begin{array}{l}\text { Aplikasi yang digunakan mempermudah dalam } \\
\text { komunikasi antar instruktur-peserta Online Course }\end{array}$ & $100 \%$ & - \\
\hline 4. & $\begin{array}{l}\text { Aplikasi yang digunakan cukup efektif dalam } \\
\text { pelaksanaan } 3 x \text { test bagi peserta Online Course }\end{array}$ & $86 \%$ & $14 \%$ \\
\hline 5. & $\begin{array}{l}\text { Aplikasi yang digunakan mempermudah dalam } \\
\text { mengetahui hasil belajar }\end{array}$ & $100 \%$ & - \\
\hline \multicolumn{4}{|c|}{$\begin{array}{l}\text { Dalam tabel Materi Pembelajaran, dapat } \\
\text { dilihat bahwa seluruh peserta didik setuju } \\
\text { bahwa Digital Book yang diberikan ternyata } \\
\text { cocok untuk mereka pelajari. Materinya } \\
\text { mudah dipahami dan bermutu, bahasanya } \\
\text { mudah dimengerti, dan contentnya } \\
\text { berkesusaian dengan siutasi sekarang. } \\
\text { Namun dalam tabel Media Pembelajaran, }\end{array}$} \\
\hline
\end{tabular}




\section{Saran untuk Program E-Learning Selanjutnya}

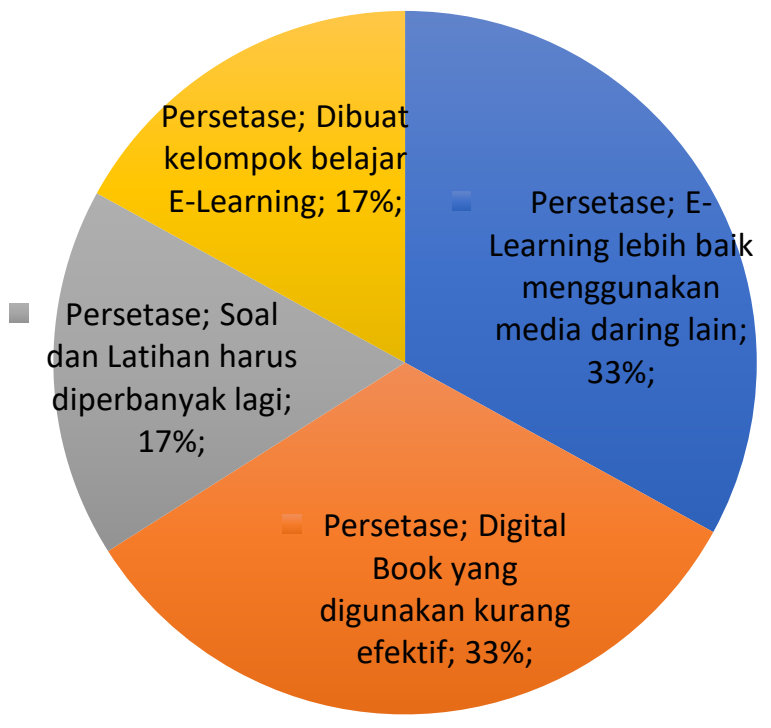

Selanjutnya adalah hasil evaluasi pembelajaran E-Learning yang didapat dari saran para partisipan. Grafik diatas memaparkan hasil tiga besar saran yang diberikan partisipan setelah melalui proses E-Learning. Sekitar $33 \%$ persen peserta didik berpendapat bahwa pembelajarn ELearning lebih baik menggunakan media daring ketimbang media aplikasi. Hal ini bisa jadi dikarenakan jika melalui aplikasi, terlebih media sosial, peserta didik akan kesulitan membedakan mana bagian untuk belajar dan yang mana bagian untum bermedia sosial. Sementara ini $17 \%$ dari partisipan berpendapat bahwa Soal dan Latihan yang diberikan belum cukup memadai untuk proses belajar mereka.
Mereka berharap kedepannya harus ada soal yang lebih banyak dan variatif agar lebih banyak hal yang mereka dapat pelajari. Memang pada akhirnya akan sedikit lebih sulit bagi sistem pembelajaran ini jika dibandingkan dengan sistem pembelajaran konvensional dimana baik dosen dan mahasiswa tidak hanya harus siap dengan perkembangan teknologi tetapi juga kesiapan materi dan bahasan yang compatible dengan sistem E-Learning. Hal ini juga diutarakan oleh Irawati \& Putra (2014) yang menyatakan bahwa baik pendidikan dan peserta didik harus diberi kesiapan dan strategi khusus untuk melaksanakan pembelajaran jarak jauk berbasih teknologi. 
Grafik 4.15 Hasil Testimoni Peserta E-Learning English Grammar

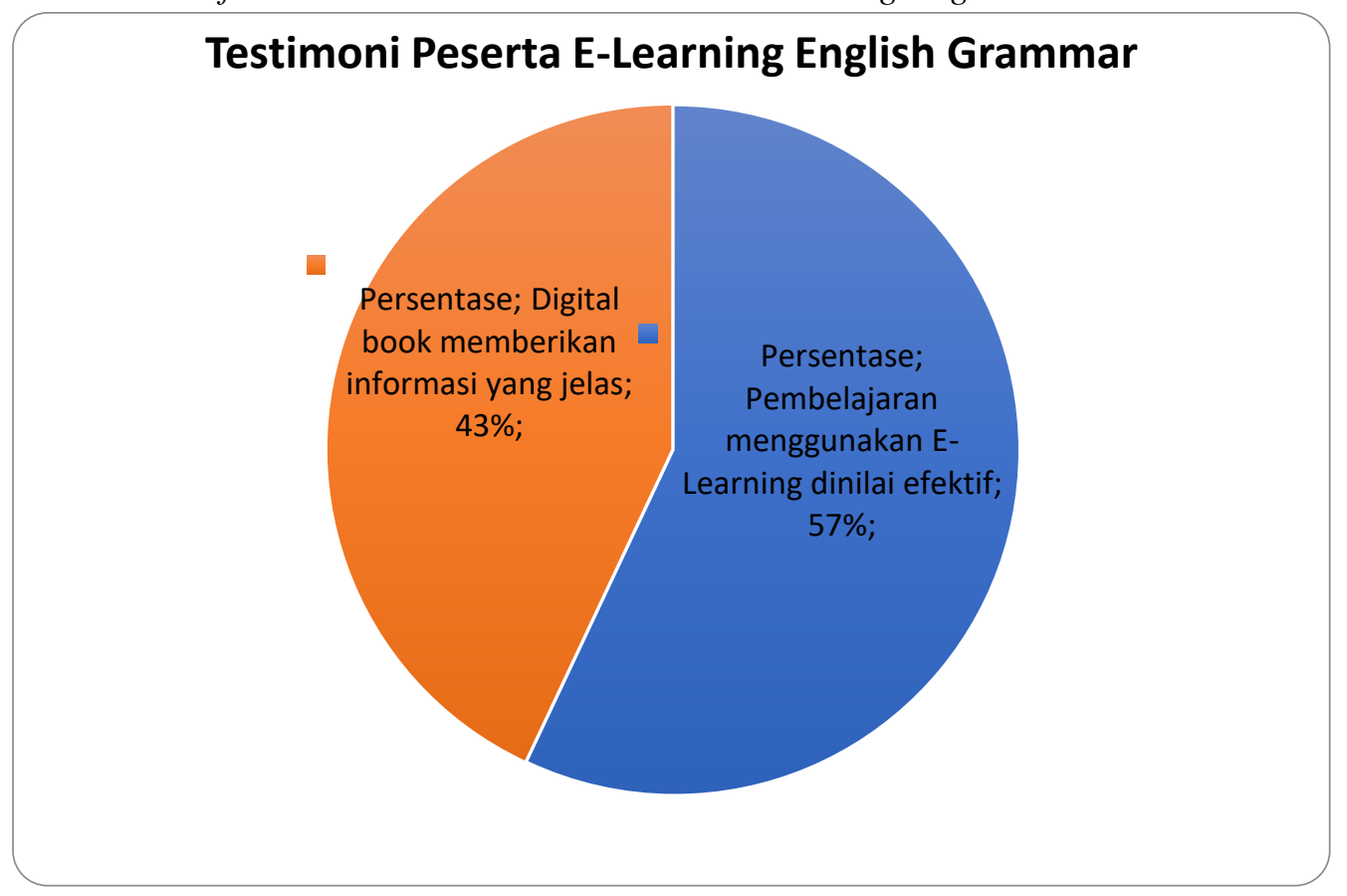

Selain melalui kotak saran, para partisipan juga diberikan kesempatan untuk membuat testimony mengenai pengalaman belajar English Grammar menggunaka sistem ELearning. Setelah dikumpulkan terdapat dua besar hasil testimony dari para peserta didik. Setengah dari mereka memberikan pengalaman tentang Digital Book yang diberikan memberikan inrmasi materi dan bahasan yang jelas, sementara sisanya mengungkapkan bahwa pembelajaran ELearning merupakan salah satu konsep belajar yang efektif untuk mempelajari English Grammar.

\section{PEMBAHASAN}

Dari hasil pengujian PWA Builder yang telah dilakukan maka dapat diambil kesimpulan bahwa performansi untuk wilayah di Indonesia adalah baik dan mobile app telah siap. PWA untuk website Pusat Bahasa ITI (https://pb.iti.ac.id) sudah diimplementasikan, namun masih terdapat kekurangan pada ketersediaan service worker untuk mendapatkan layanan ketika website dalam kondisi offline.
Untuk Hasil Evaluasi Belajar didapat bahwa terjadi Fluktuasi nilai dari seluruh partisipan Level 1. Hasil fluktuatif inilah yang menjadi salah satu bukti kekurangan dari sistem E-Learning yang disampaikan oleh Bullen (2001), yakni peserta didik tidak dapat berinteraksi secara langsung dengan dosen untuk menanyakan perihal materi yang tidak mereka mengerti. Sedangkan hasil di Level 2 terlihat lebih stabil dan cenderung naik dan membaik. Secara umum dapat dikatakan bahwa kelas level II masih bisa digunakan untuk jumlah kelas yang lebih besar melalui sistem elearning. Keberhasilan peserta didik ELearning ini menandakan hal positif yang bisa didapat dari belajar jarak jauh meski tidak melakukan tatap muka. Bisa jadi salah satu faktor dari keberhasilan ini sesuai dengan yang diungkapkan Onno Purbo (2002) yakni terpenuhi syarat dalam E-learning, yakni Sederhan, cepat, dan Personal. Digital Book yang digunakan kemungkina menjadi kunci sederhana penggunaan sistem E-Learning dimana peserta mendapatkan digital Bool secara gratis dan tidak harus mencetak fisik buku 
tersebut. Bahasa yang digunakan pun bisa menjadi kunci mudahnya peserta didik untuk mengerti digital bool tersebut. serta terdapatnya waktu bagi peserta didik untuk belajar mandiri atau sembari bertanya secara personal bisa jadi membantu mereka untuk menjadi lebih memahami materimateri pembelajaran ini.

Untuk hasil kepuasan melalui Kuisioner dari partisipan, kebanyakan dari mereka merasa masih ada kekurangan dari penggunaan aplikasi PWA. Hasil kuesioner nyatanya berbanding lurus dengan apa yang Onno Purbo (2002) sampaikan dalam teori E-Learningnya bahwa, suatu konsep E-Learning haruslah dapat diakses dengan mudah dan efisien agar dapat dimanfaatkan oleh peserta didik dengan baik tanpa harus mengalami kesulitan dalam penggunaannya. Realitanya adalah penggunaan aplikasi Whatsapp belumlah menjadi media pembelajaran E-Learning yang mudah dan efisien untuk para peserta didik meskipun aplikasi ini sudah banyak dipakai oleh masyarakat Indonesia. Sementara itu untuk testimony, Hampir seluruh partisipan setuju bahwa penggunaan Aplikasi PWA harus terus dipakai dan dikembangkan untuk pembelejaran Bahasa Inggris, tak hanya untuk English Grammar saja. Hal ini sejalan dengan hasil penelitian dari Sianturi (2018) melalui observasi dan interview mahasiswa Keperawatan yang menyatakan bahwa para mahasiswa lebih menginginkan metode pembelajaran yang interaktif, inovatif, dan sesuai dengan perkembangan teknologi.

\section{SIMPULAN}

Kesimpulan yang dapat diambil adalah aplikasi PWA berhasil terpasang dengan baik di ponsel cerdas berbasis Android maupun iOS. PWA tersebut juga telah dapat diluncurkan/dipergunakan untuk mengakses konten-konten pembelajaran Bahasa Inggris pada website Pusat Bahasa ITI pada saat kondisi jaringan online.
Ukuran file PWA yang terpasang di ponsel cerdas itu jauh lebih kecil daripada native app yang pernah dibuat dalam penelitian sebelumnya (hampir 1/100 x). Dalam penelitian ini file PWA tersebut berukuran $598 \mathrm{kB}$. PWA terpasang dengan cara yang lebih mudah dibandingkan native app, yakni hanya dengan mengunjungi website Pusat Bahasa ITI, tanpa perlu mendownload terlebih dulu dari suatu media penyimpanan atau Google Playstore / Apple Store. Berdasarkan hasil evaluasi pembelajaran English Grammar eCourse didapat kesimpulan bahwa sistem ini dapat dijadikan alternatif untuk pembelajaran yang lebih inovatif dan interaktif dibandingkan dengan pembelajaran konvesional. Pengembangan jenis media sistem E-Learning perlu dilakukan agar pembelajaran dapat berjalan lebih efisien. Penggunaan Web-Based media lebih disukai oleh partisipan. Tentu terdapat kekurangan di penelitian ini terlebih dalam jumlah partisipan yang hanya 10 orang serta variable Identifikasi dari penggunaan Aplikasi PWA yang hanya berdasarkan Service Work saja. Untuk kedepannya, penelitian selanjutnya diharapkan dapat menggunakan jumlah partisipan yang lebih banyak serta cakupan Indetifikasi keefektifan Penggunaan Aplikasi PWA ini.

\section{DAFTAR RUJUKAN}

Ahonen, T, (2011). Mobile Telecoms Industry Review. Almanac Mobile Retrieved from: http://www.tomiahonen.com/ebook/al manac.html.

Ardiansyah, I. (2013). Eksplorasi Pola Komunikasi dalam Diskusi Menggunakan Moddle pada Perkuliahan Simulasi Pembelajaran Kimia. Bandung: Universitas Pendidikan Indonesia. Berkowski. G. (2016). How to Build A Billion Dollar App, Temukan Rahasia dari Para Pengusaha Aplikasi Paling Sukses di Dunia. Terjemahan. Cetakan 
I. Tangerang Selatan: Penerbit Gemilang.

Chan, B., \& Sumaryana, Y. (2019). Penerapan Progressive Web Apps Pada Aplikasi Lowongan Kerja Dosen Universitas Perjuangan. Informatics and Digital Expert (INDEX), Vo. 1(1). Hal. 25-31.

Chandrawati, S.R. (2010). Pemanfaatan elearning dalam Pembelajaran. Jurnal Untan, Vol. 8(2).

Michael, A. (2013) Michael Allen's Guide to E-learning. Canada: John Wiley \& Sons.

Hume, D.A. (2018). Progressive Web Apps. Manning, New York.

Irawati, A., \& Putra, D. (2014). Analisis Technology Acceptance Model dalam Memahami Niat Perilaku Mahasiswa untuk menggunakan Elearning. Prosiding Seminar Bisnis dan Teknologi.

Islamiyah, M., \& Widayanti L. (2016) Efektifitas Pemanfaatan E-Learning Berbasis Website Terhadap Hasil Belajar Mahasiswa STMIK Asia Malang pada Mata Kuliah Fisika Dasar. Jurnal Ilmiah Teknologi Informasia ASIA. Vol. 10(1).

Karpagam, V. (2017). Performance Enhancement of Webpage Using Progressive Web App Features. Int. J. Innov. Res. Adv. Eng., Vol. 3(4), hal. 2349-2163.

Kurniawan, A. (2017). Analisis Performa Progressive Web Application (PWA) Pada Perangkat Mobile. Jurnal Ilmiah Informatika Komputer, Vol. 25(1).

Kurniawan, A., Areni, I. S., \& Achmad, A. (2017). Implementasi Progressive Web Application pada Sistem Monitoring Keluhan Sampah Kota Makassar. Jurnal JPE, Vol. 21(02) Hal. 34-38.

Majchrzak, T., Hansen, A., \& Gronli, T. (2018). Progressive Web Apps: the Definite Approach to Cross-Platform Development?. Proceedings of the 51st Hawaii International Conference on System Sciences.

Nurwanto. (2019). Penerapan Progressive Web Application (PWA) pada ECommerce. Technoco. Com, Vol. 18(3), hal. 227-235.
Purbo, O.W. (2002). Membangun ELearning. Jakarta: Elex Media Komputindo.

Santoso, H. (2019). Membangun Aplikasi Mobile dengan PROGRESSIVE WEB $A P P(P W A)$. Yogyakarta: Lokomedia.

Setiyadi,R., et all. (2019). Rancang Bangun Dan Perencanaan Bisnis Aplikasi Berbasis Android Untuk Pembelajaran Bahasa Inggris. Laporan Penelitian Mandiri. Institut Teknologi Indonesia.

Sianturi, S.R., \& Lisum, K. (2018). Peningkatan Motivasi Belajar melalui Evaluasi E-Learning pada Institusi Keperawatan di Jakarta dan Depok. Jurnal Pendidikan Keperawatan Indonesia, Vol. 4(2), hal. 122-130.

Tandel, S. \& Jamadar, A. (2018). Impact of Progressive Web Apps on Web App Development. International Journal of Innovative Research in Science, Engineering and Technology, Vol. 7(9).

Ardiansyah, I. (2013). Eksplorasi Pola Komunikasi dalam Diskusi Menggunakan Moddle pada Perkuliahan Simulasi Pembelajaran Kimia. Bandung: Universitas Pendidikan Indonesia. 